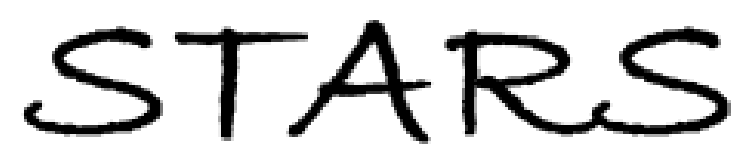

University of Central Florida

STARS

Faculty Scholarship and Creative Works

10-10-2016

\title{
Towards a Model of Electronic Word-of-Mouth and Its Impact on the Hotel Industry
}

\author{
Edwin N. Torres \\ University of Central Florida, edwin.torres@ucf.edu \\ Dipendra Singh \\ University of Central Florida, dipendra.singh@ucf.edu
}

Part of the Hospitality Administration and Management Commons, and the Tourism and Travel Commons

Find similar works at: https://stars.library.ucf.edu/ucfscholar

University of Central Florida Libraries http://library.ucf.edu

This Paper is brought to you for free and open access by STARS. It has been accepted for inclusion in Faculty Scholarship and Creative Works by an authorized administrator of STARS. For more information, please contact STARS@ucf.edu.

\section{Original Citation}

Torres, E. \& Singh, D. (2016). Towards a model of electronic word-of-mouth and its impact on the hotel industry. International Journal of Hospitality and Tourism Administration, 17(4), 472-489.

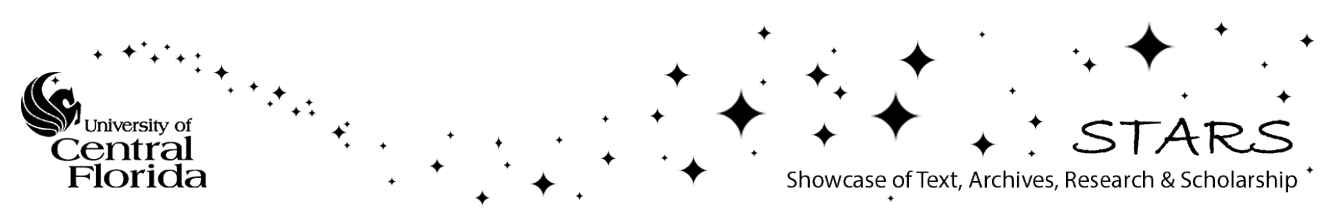




\title{
Towards a model of electronic word-of-mouth and its impact on the hotel industry
}

\begin{abstract}
Scholars and practitioners recognize that spreading word-of-mouth can play an important role in the formation of a hotel's image. However, the relationships among various measures of online customer engagement are relatively unknown. The present study analyzes the relationships and quantifies the impacts of various measures of online engagement including the number of online reviews, overall rating, and relative ranking. The researchers used path analysis on a sample of 178 hotels to study the relationships among relevant variables and build a model to explain the impact of such measures (Figure 2). The results reveal there is a positive direct effect of the number of reviews on a hotel's TripAdvisor rating. A negative direct effect was found between TripAdvisor rating and a hotel's comparative ranking. Finally, the researchers discovered that TripAdvisor rating fully mediates the relationship between the number of reviews and a hotel's comparative ranking. This paper concludes with a discussion of both the theoretical and practical implications of such findings.
\end{abstract}

KEYWORDS: Online Reviews, Lodging, Consumer-generated feedback, Social media, eWOM 


\section{INTRODUCTION}

In the course of generating a positive image for hotels, managers engage in a series of tactics to maximize positive feedback and minimize negative comments. Similarly, scholars have been fascinated with the wide-spread expansion of electronic word-of-mouth and have sought a better understanding of the consumer behaviors resulting in and those that take place as a consequence of, user-generated content (O'Connor, 2010; Ye, Law, Gu, \& Chen, 2011; Ogut \& Tas; 2012; Torres, et al., 2013). In order to expand on the nascent stream of literature, the researchers sought to explore the relationship between various measures of customer engagement. Online feedback exists for several products and services and within various industries. In previous studies, scholars have examined the impact of online feedback on book sales (Chevlier \& Mayzlin, 2006) as well as video game sales (Zu \& Zhang ,2010). Furthermore, sites such as 'Amazon' provide customers the opportunity to offer product feedback, and thus its impact has also been of interest to researchers (Mudambi \& Schuff, 2010). Another area of interest to scholars has been online movie reviews and their impact on box office sales (Duan, Gu, \& Whinston , 2008; Chintagunta, Gopinath, \&Venkataraman, 2010).

In recent years, researchers have explored the importance of consumer-generated feedback in the hotel industry. For example, Wei, Miao, and Huang (2013) examined the impact of specific and generic responses to online customer feedback. Stringam and Gerdes (2010) conducted content analysis of Expedia comments in order to determine the valence and frequency of specific feedback. Hu et al. (2012) concerned themselves with the issue of manipulation, and thus sought to develop a statistical model to quantify the likely manipulation on online feedback sites. Seeking to explore the financial impact of online feedback Ye, Law, and $\mathrm{Gu}$ (2009) developed a mathematical model to determine the impact of online review on 
sales. Although such model relied on proxy data of financial results, it still demonstrated a positive linkage between the relevant variables. In spite of the existing studies, more research is needed to ascertain the business impact of online feedback. Furthermore, the relationship between various variables of online engagement such as the number of reviews, relative ranking, and rating is relatively unknown. Given the proprietary nature of such TripAdvisor algorithms, research that sheds light concerning the relationship between the number of reviews, ranking, rating, and other relevant variables is especially important. Consequently, the researchers took on the challenge of filling this research gap.

Despite the interest emerging from various industrial sectors, the impact of consumergenerated feedback might not be equal for all products and services. In fact, Senecal and Nantel (2004) suggest that online reviews are more critical for consumers seeking to purchase experiential products. In light of the experiential nature of hospitality services, exploring the effects of consumer-generated feedback becomes a subject of outmost importance. The interest in online feedback is shared by industry practitioners. Research by online search provider Google and Ispos Media (2014) demonstrates that the internet is the number one resource for planning travel. Furthermore, their records indicate that nearly half of those surveyed used social media to share travel-related experiences. The growth is forecasted to continue and while some marketers have seen a decline in pace, social media growth around the world has not stopped and is predicted to grow over the coming year. With approximately 1.61 billion people now active in social media globally, the number of users is expected to grow to 1.82 billion next year before breaking the two billion mark in 2016 (emarketer, 2013).

In examining the previous literature on consumer-generated feedback, several streams emerge. The first group of researchers focused on the credibility of online feedback 
(Mackiewicz, 2010; Xie et al., 2011). A second group of researchers has explored the impact of online reviews on the ultimate purchase decision (Pavlou \& Domoka, 2006; Cox, Burgess, Sellitto, \& Buutjens, 2009). Yet, a third group of researchers examined the financial performance based on user-generated content (Ye et al., 2011; Ogut \& Tas, 2012). In spite of these initial efforts to understand the relationship between online reviews and financial performance, more research is necessary to further quantify such impact. Furthermore, hoteliers can gain greater perspective of the return on their investments in monitoring and generating online feedback.

Online data can yield various variables of relevance for researchers. First, online feedback sites such as TripAdvisor grant each hotel a rating of 1-5 stars based on their customer evaluations. Second, many sites reveal the number of reviews posted by customers. Research has demonstrates that with a large number of reviews, the absolute rating of a hotel is likely to increase (Melian-Gomez, Bulchand-Gidumal, \& Gonzalez-Lopez, 2013). Finally, an important, yet often overlooked element of online reviews is the overall ranking of a hotel given its competitive set (i.e. $1^{\text {st }}, 2^{\text {nd }}, 3^{\text {rd }}$ place). Given the present stream of literature and seeking to expand on the scholarly work, the following research objectives were proposed:

- To examine the relationships between various measures of customer engagement such as customer rating, ranking, and the number of reviews

- To generate a model to explain the relationships among relevant variables

- To quantify the effect of online feedback

- To provide ideas for future research as well as practical recommendations for maximizing the effectiveness of electronic word-of-mouth 


\section{REVIEW OF THE LITERATURE}

The literature review discusses four issues related to online consumer feedback. The first item discussed is that of hotelier responses to consumer feedback. As more consumers express their views online, managers have been tasked with responding to such feedback in order to both create a positive hotel image and provide good customer service. Scholars have taken interest in the patterns of response and their results are discussed in the first part of the literature review. The second part of the literature review addresses the challenges associated with online reviews. While online review sites have empowered consumers with greater access to information, they've also created the challenge of potentially deceitful reviews. This literature review exposes readers to the various studies academicians have undertaken to examine the incidence and impact of truthful versus deceitful online feedback. Online reviews can have a great impact on the consumer purchase decision process; consequently the third part of the literature review provides a summary of some key works concerning the impact of consumer reviews on the ultimate purchase decision. Despite the investment of time and effort in monitoring, responding, and taking action towards consumer feedback, little is known about its financial impact. Consequently, the final section of the literature review cites several important works that shed light on the likely financial outcomes of online consumer feedback.

\section{Online reviews and hotelier responses}

Online reviews are present and managers are conscious of this reality. However, what they do with such feedback is not always consistent. Furthermore, it can be argued that consumer-generated feedback has a great potential in terms of hotel operations intelligence. Accordingly, a hotel can use the information from electronic forms of word-of-mouth to devise 
strategies aimed at making capital improvements, address areas of opportunity through revised policies and procedures, and respond to customers in a personalized way. Schmallegger and Carson (2007) proposed that blogs and other forms of electronic word-of-mouth can provide valuable information to hotel managers, which in turn can help drive their quality results.

Torres, et al. (in press) studied the use of consumer-generated feedback for operational and quality purposes. Their research suggested that $90 \%$ of all hotel General Managers personally review feedback on a daily basis. Furthermore, TripAdvisor was found to be the outlet that most managers relied with regards to consumer feedback. The study, which consisted of a sample of hotel General Managers in 4 and 5 diamond hotels in the United States (according to AAA) ranked the actions taken by such hoteliers given feedback. It was revealed that identifying patterns of complaints was extremely important to hoteliers, whereas making changes in operating procedures based on online reviews was relatively infrequent. Additionally, those General Managers who placed greater value on online feedback were more likely to improve their perceived quality. In a similar vein, research by Hanson in Yu (2010) proposed that some hoteliers use online feedback to improve training, adjust staffing levels, and add or remove amenities.

Recent studies highlight the importance of appropriately responding to electronic feedback. For example, Wei, Miao, and Huang (2013) highlighted several elements of a hotel's response to feedback including the motivational drivers as well as the specificity of the response. Accordingly, more specific responses (as opposed to generic) were viewed in a more favorable light by consumers. In spite of the importance of responding to online feedback, Yu (2010) posited that less than $4 \%$ of the negative online reviews receive a response by a hotel manager. In order to monitor online media, some hoteliers are using technology to facilitate the process. 
For example, some are turning to companies who offer specialized software such Revinate that can scan the online world and provide summarized findings.

Research by Park and Allen (2013) identified three groups of companies with regards to their customer responses: frequent responders, infrequent responders, and non-responders. On the one hand, frequent responders stated that online feedback was mostly a fair representation of their guest's feelings. On the other hand, infrequent responders perceived reviews as extreme or biased. Based on their research results Park and Allen (2013) proposed that hotels should go beyond simply reacting to online reviews, and develop strategies to foster positive online relationships.

Whereas TripAdvisor can be of critical importance to hoteliers, other sites can also be influential on customer's opinions. Many online travel agencies such as Expedia provide former hotel guests the opportunity to post feedback online. In most cases an online travel agency requires the purchase of a service with them, thus assuring that the person posting a comment was indeed a customer of the hotel, airline, or other travel-related service. Researchers Stringam and Gerdes (2010) conducted research utilizing data from Expedia. Accordingly, the researchers separated comments based on their valence (i.e. positive, neutral, and negative) as well as the frequency of count of certain words. The researchers discovered that negative comments (those which ranked the hotel 1 or 2 out of 5) contained content regarding problems with housekeeping such as 'dirt', 'stain', and 'mold'. In contrast, positive comments (those which scored the hotel 4 or 5 out of 5) contained words related to the quality of service and staff such as 'courteous', 'attentive', and 'accommodating'. Obtaining positive reviews is a much desired goals for hoteliers. However, further research can help illuminate the impact of such reviews on a hotel's rating on consumer-generated feedback sites. Consequently, the first hypothesis was proposed: 
H1: There is a direct effect between the number of reviews received on TripAdvisor (NumRevs) and the TripAdvisor rating (TARat) received by the same hotel

Consumer-generated feedback is a subject of interest from an operational perspective. However, research also sheds light into the consumer behaviors, decision-making, and financial implications of online reviews. The following sections in this review of the literature, address each of these concerns in further detail.

\section{Challenges associated with online reviews}

As customers seek to make decisions on the purchase of products and services, they consult a variety of sources. Given the experiential nature of the hotel product as well as the inability to sample such product prior to the purchase, consumers rely heavily on electronic word-of-mouth communications (eWOM). One of the challenges associated with the use of eWOM is the credibility of such information. As a way to overcome some of these challenges, companies are investing in operational changes and partnerships to further online feedback channels. For example, TripAdvisor announced a new partnership with American Express in October of 2013. Throughout this partnership American Express members can now link their cards to TripAdvisor profiles. This will enable them to review a service they buy with the card on TripAdivsor and to have such review designated as an 'Amex Card Member Review'. The practice is likely to give users of the travel site another way to verify that the descriptions they're reading are real (American Express, 2013).

A related stream of academic research explores the credibility of the source of usergenerated content. A study by Xie et al. (2011) examined the role of personal identifying information in the ultimate purchase decision. The research revealed that reviews with personal 
information were deemed more credible by prospective consumers (Xie et al., 2011). As customers make reviews, they reveal interesting pieces of information about themselves. Research by Mackiewicz (2010) posited that customers posting online reviews use a variety of tactics to ascertain their expertise. Some examples of such claims include: a) assertions of product-specific experience, b) assertions of familiarity with related or relevant products, and c) assertions of a relevant role such as having training or education or perhaps being in a profession related to the product or service (Mackiewicz, 2010).

O’Mahony and Smyth, (2009) proposed some additional challenges with regards to online reviews including include bias, statements that are very broadly written, and the potential for information overload. At the present time, researchers debate the percentage of reviews that can be subject to some form of manipulation. On the one hand, O'Connor (2010) suggested that very few of the comments presented today at such sites can be considered suspect. On the other hand, Hu et al. (2012) proposed a statistical model to detect online review manipulation. Accordingly, around $10.3 \%$ of reviews are subject to manipulation. Another source of debate is whether customers consider online reviews to be impartial, as opposed to company-generated promotional information. Cox et.al. (2009) argued that eWOM might not be viewed as trustworthy as other sources. In contrast, Goh, Heng, and Lin (2013) compared content generated by users versus that of competitors. Although both types of content are important, user-generated content was demonstrated to have a stronger impact on purchase behaviors. Torres et al. (2013) compared the reviews or consumers and experts and discovered that despite both groups using different criteria; their scores were positively correlated. This lends further evidence to the claim that online reviews might not be as biased, as some would claim. 
Another potential concern related to online reviews is that of under-reporting. This takes place when online reviews tend to highlight extremely positive or negative feedback. Koh, Hu, and Clemons (2010) studied the phenomenon of under-reporting in two different countries: the United States and China. The researchers revealed that customers from the United States are more likely to under-report, as compared to the general population. Furthermore, the authors discovered that ratings were affected by an individual's national culture. Despite some of the challenges associated with online reviews, consumers use such information to inform their purchase decision. The following section explores the literature which expands on this subject.

\section{Online reviews and customer decisions}

Prospective customers can use online reviews in a variety of ways. Some might use it to simply scan the environment or the equivalent of the retail practice of 'window shopping'. In contrast, other customers use it as a deciding factor in their purchase of a product or service. With different customers traveling to different destinations, staying at different hotels, with different plans, and different travel motivations, it can be challenging to ascertain the role that eWOM plays in their search. Fortunately, scholars have explored the various uses and relative importance of eWOM on customer decision-making. For example, Cox, et al. (2009) proposed that consumers are more likely to utilize consumer - generated content at the information gathering stage of the purchase decision process. Research has also demonstrated that prospective customers rarely read comments beyond the first two pages in feedback sites (Pavlou \& Domoka, 2006). Sparks and Browning (2011) discovered that numerical ratings in consumer reviews were only relevant when accompanied by verbal feedback. 
In their study of consumer decision making and social media, Vermeulen and Seegers (2009) reveled that reviews can help consumers move from a universal set of choices to a consideration set. The researchers also proposed that online reviews had a greater impact on independent hotels (Vermeulen \& Seegers, 2009). In support of this, Papathanassis and Knolle (2011) suggest that online reviews are considered by customers as additional content to aid in their search for alternatives and purchase decision. Finally, the authors argue that online review adoption will depend on various factors including the richness of the content and its accessibility (Papathanassis \&Knolle, 2011). Given the fact that consumers use the information from online reviews to inform their purchase decision, and given the vast amounts of information when compared to the limited time of consumers, it would be pertinent to study a the importance of a hotel's ranking on TripAdvisor (i.e. $1^{\text {st }}, 2^{\text {nd }}, 3^{\text {rd }}$ within their market competitive set). Furthermore, the formula for calculating the TripAdvisor popularity index is kept proprietary. While TripAdvisor (2013) admits to using factors such as the number of reviews, quality of reviews, and age of the reviews; the importance of each of these factors is unknown to the general public. Consequently, the second research hypothesis was proposed as follows:

H2: The rating received on TripAdvisor (TARat) has a direct effect on the TripAdvisor Ranking (TARank)

Researchers have also proposed practical solutions to improve a hotel's image on online feedback sites. More specifically, Shmalegger and Carson (2007) suggested hiring an experienced and professional blogger and letting employees blog about their companies. However these methods can be controversial due to the potential bias. Noone, McGuire, and Rohlfs (2011) suggested that Revenue Managers have various opportunities to engage with customers through various social media outlets. Information in online feedback sites can help 
Revenue Managers adjust pricing as well as the configuration of promotions and packages, and the execution of push strategies. Other decisions, which can be informed by consumer-generated media, include finding the appropriate distribution channels and developing micro-sites targeted at specific customer groups (Noone, et al., 2011). As demonstrated, the literature on consumergenerated feedback has explored various aspects of decision making. Additionally, researchers have begun exploring its impact for operational purposes and its likely financial outcomes. The following section explores the financial impact of online feedback.

\section{The financial outcomes of online feedback}

Given the amount of consumer-generated feedback available online, scholars have sought to gain a better understanding of this emerging field. As hotels seek to maximize their revenues and resulting profits from online booking transactions, many have shown curiosity towards measuring such impact. As one of the earlier examples of academicians seeking to quantify the impact of online feedback, Ye, Law, and Gu (2009) developed a mathematical model to explain the effects of consumer-generated feedback on hotel sales. Such model revealed that $10 \%$ improvement in reviews led to a $4.4 \%$ increase in sales. Industry managers have also expressed curiosity about the impact that online reviews have on business results. In an interview, Brian Ferguson (Executive Vice-President of Expedia) disclosed that according to his records "A onepoint increase in a review score equates to a 9\% increase in ADR" (Lynch, 2012). As hoteliers seek to attract more traffic to their proprietary websites, various solutions have been proposed. As an example, Zhang, et al. (2011) explored the impact of online feedback and traffic to a businesses' website. The results of their research pointed out to a positive relationship between positive reviews and traffic to a restaurant's website. 
Online reviews can impact the sales of other products and services. Chintagunta et al. (2010) studied the impact of movie reviews in box office sales using "Yahoo! Movies". The authors discovered that given a specific market, the valence of the comments influenced box office sales performance. However, as it related to national aggregate of box office sales, the number of reviews was the primary driver of sales performance. Though many are concerned about the negative impacts, user-generated content can be used as a marketing tool. For example, some hotels have created photo contests for guests, and encouraged them to share videos and stories. Furthermore, hotels have used social networking to help guests interact with one another before a stay and create contacts to socialize during their visit (Kasavana, Nusair, \& Teodosic, 2010). As another example, travel company Contiki utilizes their own social networking platform to help tour members interact with one another before meeting for their tour (Contiki, n.d.).

In yet another study, Ye, et al. (2011) conducted explored the impact of positive online reviews on hotel sales. Accordingly a higher valence (i.e. more positive) in the average review led to an increased number of reviews. Furthermore, they discovered that the variability in such comments was not as critical as the overall rating given by consumers in terms of generating a greater number of reviews (Ye, et al., 2011). As a drawback of this research as well as others seeking to explore the financial impact of consumer feedback was the lack financial data. In light of this, the number of reviews was used as a proxy for hotel sales. The number of reviews a hotel obtains can be critical towards its online image, ranking, and consumer decisions. Given the existing literature and seeking to expand and create new knowledge, the third hypothesis was proposed as follows: 
H3: The number of reviews a hotel receives (NumRevs) has a direct effect on its TripAdvisor Ranking (TARank)

Online reviews are used to explore various hotels and destinations in different parts of the world. Whereas TripAdvisor is a leader in online feedback in the United States, other countries also have means of posting their feedback. Research by Ogut and Tas (2012) examined the impact of both expert rating and consumer ratings. The researches sought to unveil the impact of experts and consumer's opinions on hotel sales in two major tourist destinations: Paris and London. Results suggest that consumer ratings impact the number of reviews more so than the ratings of experts. Furthermore, the authors revealed a positive relationship between consumer ratings and the hotel's average price of a standard double room in each of these cities. (Ogut \&Tas, 2012). These studies shed light as to the financial outcomes of consumer-generated feedback. However, more research is necessary to prove such relationships on various measures of sales and profitability.

\section{METHODOLOGY}

In order to obtain and analyze the data needed for this study, the researchers gathered a sample of 178 hotels around the United States. Hotels represent a cross-section of corporate, managed, and independent hotels. They were also located in different cities and catered towards different guests (i.e. business, leisure, convention). Relevant data included the hotel's rating, ranking and number of reviews. A hotel rating is the rating that is given by Trip Advisor to each hotel (i.e. 1, 2, 3, 4, 5 stars) based on the totality of the consumer comments received. The formula used to give the hotel ranking is kept proprietary by TripAdvisor. The ranking relates to the placement of each hotel within its competitive set (i.e. a hotel is $1^{\text {st }}, 2^{\text {nd }}$, or $3^{\text {rd }}$ in a given 
city). The number of reviews indicates the total number of reviews recorded by TripAdvisor for a given hotel. Information about the hotels was gathered during the Fall of 2013.

Path analysis was the main statistical method utilized to analyze the data. Path analysis is a quantitative methodology that enables researchers to ascertain whether a certain variable (i.e. mediating variable) has an effect on the relationship between two other variables. Consequently, path analysis was deemed an appropriate statistical methodology for this study. In order to test for the mediating effect of TripAdvisor Rating (TARat) on Trip Advisor Ranking (TARank), the researchers followed the procedure formulated by Baron and Kenny (1986). Kenny (2014) explains the steps involved in this procedure as:

"Step 1: show that the causal variable is correlated with the outcome variable; Step 2: show that the casual variable is correlated with the mediator; Step 3: show that the mediator affects the outcome variable; Step 4: to establish that M completely mediates the X-Y relationship, the effect of X on Y controlling for M should be zero".

Several regression models were estimated for the outcome variable. The mediating variable was regressed on the number of reviews (NumRevs), and the outcome variable was regressed on both the mediator and the NumRevs. Path analysis was deemed a relevant method of analysis due to its ability to examine the mediation effects among variables. Since the number of reviews was hypothesized to have an impact on the ranking, this particular research method was chosen for analysis.

According to Baron and Kenny (1986), the following conditions must be met to establish mediation: first, the NumRevs must affect the mediator in the first regression equation; second, the TARat must be shown to affect the outcome variable in second regression equation; and 
third, the mediator must affect the outcome variable in the third regression equation. Mediation occurs if the effect of the NumRevs on the outcome variable is smaller when the mediator is controlled. Perfect mediation means that the NumRevs has no effect on the outcome variable when mediator is controlled. A path analysis model (Figure 1) was proposed for testing the mediating effect of TARat using IBM SPSS AMOS 21 to analyze the regression equations.

\section{>> Insert Figure 1 Here $<<<$}

\section{RESULTS}

A path analysis constituting a set of regression analysis was performed between the hotel's overall online ranking, TARat, and NumRevs. Analysis was performed using IBM SPSS AMOS 21.0. Pearson's bivariate correlations are presented in Table 1. The plot of residuals indicates that the data follow linearity and normality conditions without any homoscedasticity. The tolerance values of the independent variables gave no indication of multicollinearity, with the highest tolerance value being less than 1.04. Since the variables were mostly scaled differently, their relative significance can be compared only on the basis of the standardized beta coefficient.

\section{>> Insert Table 1 Here $<<<$}

Results indicate that TripAdvisor rating fully mediated the effect of the number of reviews on the variable TripAdvisor Ranking $(\mathrm{p}<0.001$ ). As Figure 2 illustrates, the standardized regression coefficients between NumRev and TARat were statistically significant $(\mathrm{F}=5.4, \mathrm{p}<.05)$, thus supporting the first hypothesis. The standardized regression coefficient between TARat and TARank was also significant $(\mathrm{F}=40.08, \mathrm{p}<.001)$, lending support for the second hypothesis. The standardized indirect effect was $(.20)(-.48)=-.094$. The research team 
further tested the significance of this indirect effect by utilizing Sobel's test statistics $(p<.001)$. Sobel tests whether a mediator variable significantly carries the influence of an independent variable to a dependent variable (i.e., whether the indirect effect of the independent variable on the dependent variable through the mediator variable is significant). Whenever a mediator is introduced to a regression equation, the effect of the independent variable can be reduced. Consequently, the Sobel test ensures that the effect of the mediator remains significant in spite of the potential reduction in the effect of the independent and dependent variable on one another. Consequently. The researchers discovered that there was no direct significant effect of NumRevs on TARank $F=.13, p>.05)$. Since there was a significant indirect effect of NumRevs on TARank through mediating variable TripAdvisor rating, perfect mediation was witnessed through the results. In light of this, the third research hypothesis was not supported.

\section{>> Insert Figure 2 here $<<<$}

The first research hypothesis proposed that there is a significant relationship between the number of reviews received through an online feedback site and the hotel's TARat on online feedback sites. Such hypothesis was supported by the results of the regression analysis. A positive coefficient indicates a direct positive effect of number of reviews on the TARat, a higher number of reviews will result in a higher rating for a hotel. The second hypothesis posited that there is a significant relationship between the hotel's overall rating (i.e. 1, 2, 3 stars) on an online feedback site and the hotel's overall ranking on online feedback sites. Such hypothesis was supported by the results of the analysis. The negative sign of the coefficient denotes an inverse relationship between rating and ranking of the hotels. A higher rating will result in lower numeric ranking for the hotels on websites. Lastly, the third hypothesis proposed that there exists 
a significant direct relationship between the number of reviews and the hotel's overall ranking on online feedback sites. This hypothesis was not supported by the results of the regression analysis.

\section{DISCUSSION}

\section{Relationships between reviews and ranking}

As managers and academicians seek a better understanding of the use and impact of online feedback, the present study sought to further clarify such relationships. One of the key findings of this study was that Trip Advisor ratings fully mediate the relationship between the number of reviews and the relative online ranking. Previous research suggested that with a large number of reviews, the hotel evaluation could potentially be improved (Melian-Gomez et al., 2013). Additionally, scholars have attempted to create mathematical models to assess the financial impact of online feedback using proxy data (Ye et al., 2009). Every hotel wants to be at the top of their competitive set. Having a rank of first place within a given market can prove to be beneficial for a hotel given the increased visibility and perceived service quality. Given the relationship presented, hoteliers can strive to increase their number of reviews on this site. Whereas many managers fear guest comments online and react to their content, a better strategy might be to encourage customers to post online, especially if favorable feedback is expected.

\section{Relationships between reviews and rating}

During the course of analysis, the researchers discovered that the number of reviews had a positive direct effect on Trip Advisor rating. This supports and extends the findings of Ogut and Tas (2012), which discovered a relationship between ratings and the pricing of a standard double room in two European cities. In the past, academic research has focused on examining the 
content of the comments on TripAdvisor and similar feedback sites (Kasavana et al., 2010; O’Connor, 2010; Stringam \& Gerdes, 2010). Nevertheless, less attention has been paid to the quantitative date available from such sites. The present study investigated the effects of numerical data provided through such sites. Previous research suggested that numerical information is of greater impact when accompanied by verbal feedback (Sparks \& Browning, 2011). Consequently, hoteliers might need to pay attention to both qualitative comments and quantitative ratings in order to manage their image on online feedback sites. First and foremost, a hotel needs to focus on generating a good volume of comments if they are to improve their image. Consistent with research by Wei et al. (2013), hoteliers should strive to respond to such feedback in a personalized way.

\section{Relationships between rating and relative ranking}

As hypothesized, the present study discovered that there was a significant negative direct effect of TripAdvisor rating and TripAdvisor ranking. As a hotel increases its rating (i.e. moves from 1 to 5 stars), it will decrease its comparative ranking (i.e. move from $20^{\text {th }}$ to $1^{\text {st }}$ place within its competitive set). Therefore, the second item of importance for hoteliers (after producing an adequate volume of customer reviews) should be to improve the rating per guest review. Torres et al. (in press) discussed some of the operational responses to guest feedback. Accordingly, hotel General Managers can make capital investment decisions, changes in training and operating procedures, as well as the addition or removal of amenities, based on online guest feedback. Furthermore, hoteliers can make personal invitations to their delighted guest to post comments in various customer feedback sites. More importantly, by reviewing positive feedback and seeking to perpetuate actions that delight the guest, a hotel can engage in a virtuous upward cycle of guest feedback. Better ratings are likely to result in greater perceived service quality and 
customer satisfaction (Torres et al., 2013). Positive consumer-generated feedback can result in increased traffic to a company's proprietary website (Zhang, et al., 2011) and improved financial outcomes (Ogut \& Tas, 2012; Ye et al., 2009).

\section{Re-examining research objectives}

In the introduction section, several research objectives were proposed. The following summarizes how each was addressed throughout the study:

- To examine the relationships between various measures of customer engagement such as customer rating, ranking, and the number of reviews

$\circ$ The present research demonstrated that a direct effect existed between the number of reviews in TripAdvisor and the rating received by the same hotel. Similarly, a hotel's TripAdvisor rating had a direct effect on its TripAdvisor rankings. This lends support to the first and second hypothesis. The third hypothesis was not supported, thus demonstrating that there is no significant direct effect of the number of reviews on TripAdvisor ranking. A possible explanation for this is TripAdvisor's proprietary algorithm. Although, the review site explains that they utilize number of reviews, timing of reviews, and quality of reviews, the exact proportion of their popularity index is kept secret by the company (TripAdvisor, 2013).

- To generate a model to explain the relationships among relevant variables

- A path model was developed to explain the relationship among variables. According to Figure 2, The TripAdivsor rating fully mediates the relationship between the number of reviews and TripAdvisor ranking. 
- To quantify the effect of online feedback

- The effects of online feedback were quantified, as demonstrated in Table 1

- To provide ideas for future research as well as practical recommendations for maximizing the effectiveness of electronic word-of-mouth

- Several recommendations were proposed in throughout the paper including encouraging larger number of reviews through links to TripAdvisor, presenting opportunities to provide feedback while on-site, having links to Trip Advisor in a company's website, E-Mail signature and other relevant places. Additionally, managers should strive to provide personalized responses to guest feedback and take action to improve upon areas of opportunity as well as to perpetuate patterns of positive feedback. Research by $\mathrm{Yu}(2010)$ revealed that only $4 \%$ of negative online reviews receive a response by management. Additionally Wei et al. (2013) highlighted differences between generic and specific responses. Consequently it's important for managers to not only answer, but to do so in a personalized manner. Future research ideas were provided including examining these relationships at an international level, doing longitudinal analysis, examining the specific search process of customers via experimental methodology, ascertain the relative importance of online feedback as compared to other sources of information, determining the relative importance of online feedback based on hotel type or purpose of travel (i.e. business, leisure, conference), and obtaining qualitative data concerning consumer's willingness and motivation to post electronic feedback. 


\section{CONCLUSION}

Beyond gathering intelligence and responding to such information, hotels should use various social media platforms to engage with their guests before, during, and after their visit. Kasavana, et al. (2010) discovered that some best practices of hotels include using social networking to help guests interact with one another before a stay and create contacts to socialize during their visit. In light of this, hotels can use technology not only to maintain or sustain their image, but also to build positive customer-to-customer interactions, which could result in greater satisfaction. Furthermore, using various technology platforms to engage with the guests prior to their stay may render an image of personalization and contribute to a positive experience even before the hotel stay. Noone et al. (2011) proposed that revenue managers can adjust pricing, configure packages, and make decisions on distribution channels informed by online consumer

feedback. Although many managers have viewed TripAdvisor and other review sites in terms of customer satisfaction, it would be advisable to start examining these as means to generate higher rates, occupancies, and traffic to a company's website. More traffic to a hotel's proprietary site might mean less reliance on online travel agencies, commissions and other discounting mechanisms. This would be consistent with research by Zhang et al. (2011) which discovered links between online feedback and traffic to a company's proprietary website.

The present study utilized information regarding guest engagement through one online feedback website. More research could examine similar relationships within other social media platforms. All of the hotels under study are based in the United States. Therefore, future research could explore similar topics in international hotels. The present study uses quantitative information regarding guest feedback, but does not explore the reasons or motivations for the 
customer's postings. Future research could further explore such motivations from a qualitative perspective.

Both scholars and practitioners have been fascinated with the topic of online guest feedback. The present study demonstrates the relationship among various quantitative measure of guest engagement in an online feedback site. As academicians seek to gain a better understanding of consumer behaviors resulting in the generation of feedback and managers seek to improve such feedback for their operations, guest service as a whole and feedback emerging from such service has great potential to improve. Today more than ever, information regarding a guest's thoughts, feelings, and preferences is readily available online. It can be easy to focus on the challenges in an attempt to minimize negative impact of guest feedback; however the greater potential lies in encouraging, responding, and acting upon such feedback. In this manner hoteliers will benefit from a more satisfied, loyal, and profitable guest; and guests will benefit from improved customer-driven service quality.

\section{REFERENCES}

American Express (2013). American Express and TripAdvisor team up to launch enhanced travel planning experience: The reviews are in. Retrieved electronically on January 2014 from: http://about.americanexpress.com/news/pr/2013/amex-tripadvisor-team-up-enhancedtravel-plan.aspx

Baron, R., \& Kenny, D. (1986). The moderator-mediator variable distinction in social psychological research: Conceptual, strategic, and statistical considerations. Journal of personality and social psychology, 51 (6), 1173-1182. 
Chintagunta, P., Gopinath, S., \& Venkataraman, S. (2010). The effects of online user reviews on movie box office performance: Accounting for sequential rollout and aggregation across local markets. Marketing Science, 29 (5), 944-957.

Chevlier, J., \&Mayzlin, D. (2006). The effect of word-of-mouth on sales: Online book reviews. Journal of Marketing Research, 43 (3), 345-354.

Contiki (n.d.). Retrieved electronically on March 2014 from: http://www.contiki.com/pages/3652-meet-ups

Cox, C., Burgess, S., Sellito, C., \&Buultjens, J. (2009).The role of user-generated content in tourists' travel planning behavior.Journal of Hospitality Marketing \& Management, 18, 746-764.

Duan, W., Gu, B., \&Whinston, A. (2008). Does online reviews matter? - An empirical investigation of panel data. Decision Support Systems, 45 (4), 1007-1016.

EMarketer (2013). India leads worldwide social networking growth. Retrieved electronically on January 2014 from: http://www.emarketer.com/Article/India-Leads-Worldwide-SocialNetworking-Growth/1010396

Goh, K., Heng, C., \& Lin, Z. (2013). Social media brand community and consumer behavior: Quantifying the relative impact of user- and marketer-generated content. Information Systems Research, 24 (1), 88-107.

Google \& Ispos MediaCT Travel Study (2014). Retrieved electronically on January 2014 from: http://www.reviewpro.com/exclusive-advice-for-hotels-from-google-tripadvisorfacebook-and-twitter-29420 
Hu, N., Bose, I., Koh, N., \& Lui, L. (2012). Manipulation of online reviews: an analysis of ratings, readability, and sentiments. Decision Support systems, 52 (3), 674-684.

Kasavana, M., Nusair, K., \&Teodosic, K. (2010). Online social networking: Redefining the human web. Journal of Hospitality and Tourism Technology, 1(1), 68-82.

Kenny, D. (2014, October 29). Mediation. Retrieved electronically on December 8, 2014 from: http://davidakenny.net/cm/mediate.htm

Koh, N., Hu, N., \& Clemons, E. (2010). Do online reviews reflect a product's true perceived quality? An investigation of online movie reviews across cultures. Electronic commerce research and applications, 9, 374-385.

Litvin, S., Goldsmith, R., \& Pan, B. (2008).Electronic word-of-mouth in hospitality and tourism management. Tourism Management, 29 (3), 458-468.

Lynch, J. (2012, January 10). Online review reputation management trends for hotels in 2012. Sabre Hospitality Solutions. Retrieved on February 6, 2012 from http://www.sabrehospitality.com/blog

Mackiewicz, J. (2010). Assertions of expertise in online product reviews. Journal of Business and Technical Communication, 24 (1), 3-28.

Melian-Gomez, S., Bulchand-Gidumal, J., \& Gonzalez-Lopez, B. (2013). Online customer reviews: As participation increases, better evaluation is obtained. Cornell Hospitality Quarterly, 54 (4).

Mudambi, S., \& Schuff, D. (2010). What makes a helpful online review? A study of customer reviews on Amazon.com., MIS Quarterly, 34 (1), 184-200. 
Noone, B., McGuire, K., \&Rohlfs, K. (2011). Social Media meets hotel revenue management: Opportunities, issues, and unanswered questions. Journal of Revenue and Pricing Management.10 (4), 293-305.

O’Connor, P. (2010). Managing a hotel's image on TripAdvisor.Journal of Hospitality Marketing \& Management, 19, 754-772.

Ogut, H., \&Tas, B. (2012). The influence of internet customer reviews on online sales and prices in the hotel industry. The Service Industries Journal, 32 (2), 197-214.

O’Mahony, M., Smyth, B.(2010). A classification-based reviewer recommender. KnowledgeBased Systems, 23 (4), 323-329.

Papathanassis, A., \& Knolle, F. (2011). Exploring the adoption and processing of online holiday reviews: A grounded theory approach. Tourism Management, 32, 215-224.

Park, S., Allen, J. (2013). Responding to online reviews: Problem solving and engagement in hotels. Cornell Hospitality Quarterly, 54 (1), 64-73.

Pavlou, P. A., \&Dimoka, A. (2006). The nature and role of feedback text comments in online marketplaces: Implications for trust building, price premiums, and seller differentiation. Information Systems Research, 17(4), 392-414.

Schmallegger, D., \& Carson, D. (2007). Blogs in tourism: Changing approaches to information exchange. Journal of Vacation Marketing, 14(2), 99-110.

Senecal, S., \&Nantel, J. (2004).The influence of online product recommendations on consumers' online choices.Journal of Retailing,80, 159-169.

Sparks, B. A., \& Browning, V. (2011).The impact of online reviews on hotel booking intentions and perception of trust. Tourism Management, 32 (6), 1310-1323. 
Stringam, B., \& Gerdes, J. (2010). An analysis of word-of-mouse ratings and guest comments of online hotel distribution sites. Journal of Hospitality Marketing and Management, 19 (7), 773-796.

Torres, E. N., Adler, H., Lehto, X., Behnke, C., \& Miao, L. (2013). One experience and multiple reviews: The case of upscale US hotels. Tourism Review, 68 (3), 3-20.

Torres, E.N., Adler, H., Behnke, C., Miao, L., Lehto, X. (in press). The use of consumer generated feedback in the hotel industry: Current practices and their effects on quality. International Journal of Hospitality and Tourism Administration, 16 (3).

TripAdvisor (2013, July 26). FAQ-TripAdvisor popularity ranking: Key factors and how to improve. Retrieved electronically on December 3, 2014 from http://www.tripadvisor.com/TripAdvisorInsights/n684/tripadvisor-popularity-rankingkey-factors-and-how-improve

Trusov, M., Bucklin, R., \&Pauwels, K. (2009). Effects of word-of-mouth versus traditional marketing: Findings from an internet social media site. Journal of Marketing, 73, 90-102.

Vermeulen, I. E., \&Seegers, D. (2009). Tried and tested: The impact of online hotel reviews on consumer consideration. Tourism Management,30, 123-127.

Wei, W., Miao, L., \& Huang, Z. (2013). Customer engagement behaviors and hotel responses. International Journal of Hospitality Management, 33, 316-330.

Westbrook, R. (1987). Consumption-based affective responses and post-purchase processes. Journal of Marketing Research, 24 (3), 258-270.

Williams, R., Van der Wiele, T., Van Iwaarden, J. , \& Eldridge, S. (2010). The importance of user-generated content: The case of hotels. The TQM Journal, 22(2), 117-128. 
Xie, H., Miao, L., Kuo, P., \& Lee, B. (2011). Consumers' responses to ambivalent online reviews: The role of perceived source credibility and pre-decisional disposition. International Journal of Hospitality Management, 30, 178-183.

Ye, Q., Law, R., \&Gu, B. (2009). The impact of online user reviews on hotel room sales. International Journal of Hospitality Management, 28, 180-182.

Ye, Q., Law, R., Gu, B., \& Chen, W. (2011). The influence of user-generated content on travel behavior: An empirical investigation on the effects of e-word-of-mouth to hotel online bookings. Computers in Human Behavior, 27, 634-639.

Yu, R. (2010, March 23). Hotel managers monitor online critiques to improve service. USA Today. Retrieved February 6, 2012 from http://www.usatoday.com

Zhang, Z., Ye, Q., Law, R., \& Li, Y. (2011). The impact of e-word-of-mouth on the online popularity of restaurants: A comparison of consumer reviews and editor reviews. International Journal of Hospitality Management, 29(4), 694-700.

Zhu, F., Zhang, X. (2010). Impact of online consumer reviews on sales: The moderating effect of product and consumer characteristics. Journal of Marketing, 74, 133-148. 